\title{
A new record of Nymphaea (Nymphaeaceae) for Flora of Nepal
}

\author{
Bhakta B. Raskoti ${ }^{*}$, Rita Ale ${ }^{1}$ and Ganga D. Bhatt ${ }^{2}$ \\ ${ }^{1}$ Pokharathok 9, Arghakhanchi, Nepal; ${ }^{2}$ National Herbarium and Plant Laboratories Department of Plant Resources, \\ Godawari, Lalitpur, Nepal
}

\begin{abstract}
Occurrence of Nymphaea lotus var. pubescens Willd. (Nymphaeaceae) in Nepal is reported. Detailed description, illustration and relevant notes are provided.

Key words: Hairy water lily, taxonomy, conservation status.
\end{abstract}

The genus Nymphaea comprises 50 species around the world and distributed in south East Asia (Dezhi et al 2001). Nymphaea lotus var. pubescens Willd. is known as hairy water lily and distributed in China, Bangladesh, India, Indonesia, Myanmar, New Guinea, Pakistan, Philippines, Sri Lanka, Thailand and Vietnam (Dezhi et al 2001).

There are two species of Nymphaea in Nepal, namely Nymphaea nouchali N.L. Burm. and Nymphaea rubra Roxb. ex Andrews distributed in the tropical region (Press et al. 2000; Rajbhandari and Bhatt 2011). Nymphaea lotus var. pubescens is not previously reported so far from Nepal (Hara et al 1978; Press et al 2000; Bista et al 2001). There is no record of herbarium specimen in the National Herbarium and Plant Laboratories (KATH) and Tribhuvan University Central Herbarium (TUCH). In this study, Nymphaea lotus var. pubescens have been collected by the authors from the Banke District, of Mid-Western Nepal and the specimens are deposited at KATH. Nymphaea lotus var. pubescens is distinct in characters with other Nymphaea species having pubescence in the leaf petiole, flower pedicel and ventral surface of leaves. (Figures 1 \& 2).

*For correspondence,

e-mail: bbraskoti@gmail.com; tel: 97715537055
Nymphaea lotus var. pubescens (Willd.) Hook.f. \& Thoms., Fl. Brit. India. 1: 114. 1872.

Nymphaea pubescens Willd., Sp. Pl. 2: 1154. 1799.

Perennial floating herbs. Rhizomes erect with slender stolons. Leaf papery, ovate-elliptic to orbicular, 8-15×5-15 cm, abaxial surface densely pubescent, peltate, base deeply cordate, margin dentate and teeth acute to subspinose. Flower emergent, red, $10 \mathrm{~cm}$ across. Calyx incorporated on receptacle circular; sepals oblong, 5-7×1.5-2 cm, veined, obtuse. Petals oblong, 6-7×1-1.5 cm, veined, subacute. Filament of inner stamens wider than anther. Carpels fused. Stigma rays, with linear appendages carpillary. Fruit ovoid to subglobose.

Flowering: October-November.

Habit and habitat: Open shallow ponds near roadsides, at an altitude of 160-300 meters.

Distribution: Nepal (Mid-western Nepal), Bangladesh, China, Indonesia, India, Myanmar, New Guinea, Pakistan, Philippines, Sri Lanka, Thailand, Vietnam.

Conservation status: Threatened due to habitat destruction, overexploitation for ornamental and religious use.

Note: The newly reported taxa is closely related to Nymphaea rubra but differs from the later by smaller leaf size and pubescens in the ventral surface of leaves and in the petiole. 
Specimen examined: Mid-western Nepal, Banke District, Nepalgunj at altitude of about 160 m, Oct 22, 2010, Raskoti and Ale 210 (KATH).

\section{Acknowledgements}

The authors are thankful to the curator of the National Herbarium and Plant Laboratories Godawari, Lalitpur (KATH) and Tribhuvan University Central Herbarium (TUCH) for allowing us to examine herbarium specimens.

\section{References}

Bista M.S., Adhakari M.K. and Rajbhandari K.R. 2001. Flowering Plants of Nepal (Phanerograms). Department of Plant Resources, Kathmandu, Nepal.

Dezhi F.U., Wiersema J.H. and Padgett D. 2001. Flora of China. Vol. 6. Missouri Botanical Garden Press, Missouri, USA.

Hara H., Stearn W.T. and Williams L.H.J., eds. 1978. An Enumeration of the Flowering Plants of Nepal. British (Natural History) Museum, London, UK.

Press J.R., Shrestha K.K. and Sutton D.A. 2000. Annotated Checklist of the Flowering Plants of Nepal. The Natural History Museum, London, UK.

Rajbhandari K.R. and Bhatt G.D. 2011. Nymphaeaceae. In: Catalogue of Nepalese Flowering Plants-II (K.R. Rajbhandari, K.R. Bhattrai and S.R. Baral, eds.), pp 27-28. National Herbarium and Plant Laboratories, Lalipur, Nepal.

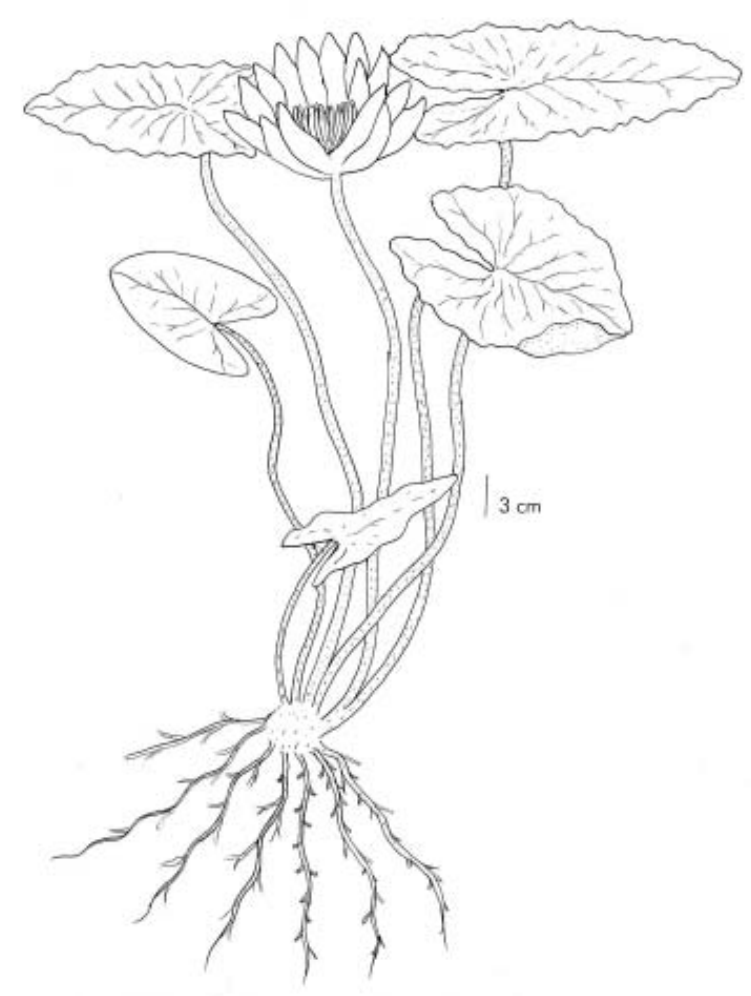

Figure 1. Flowering plant of Nymphaea lotus var. pubescens. 

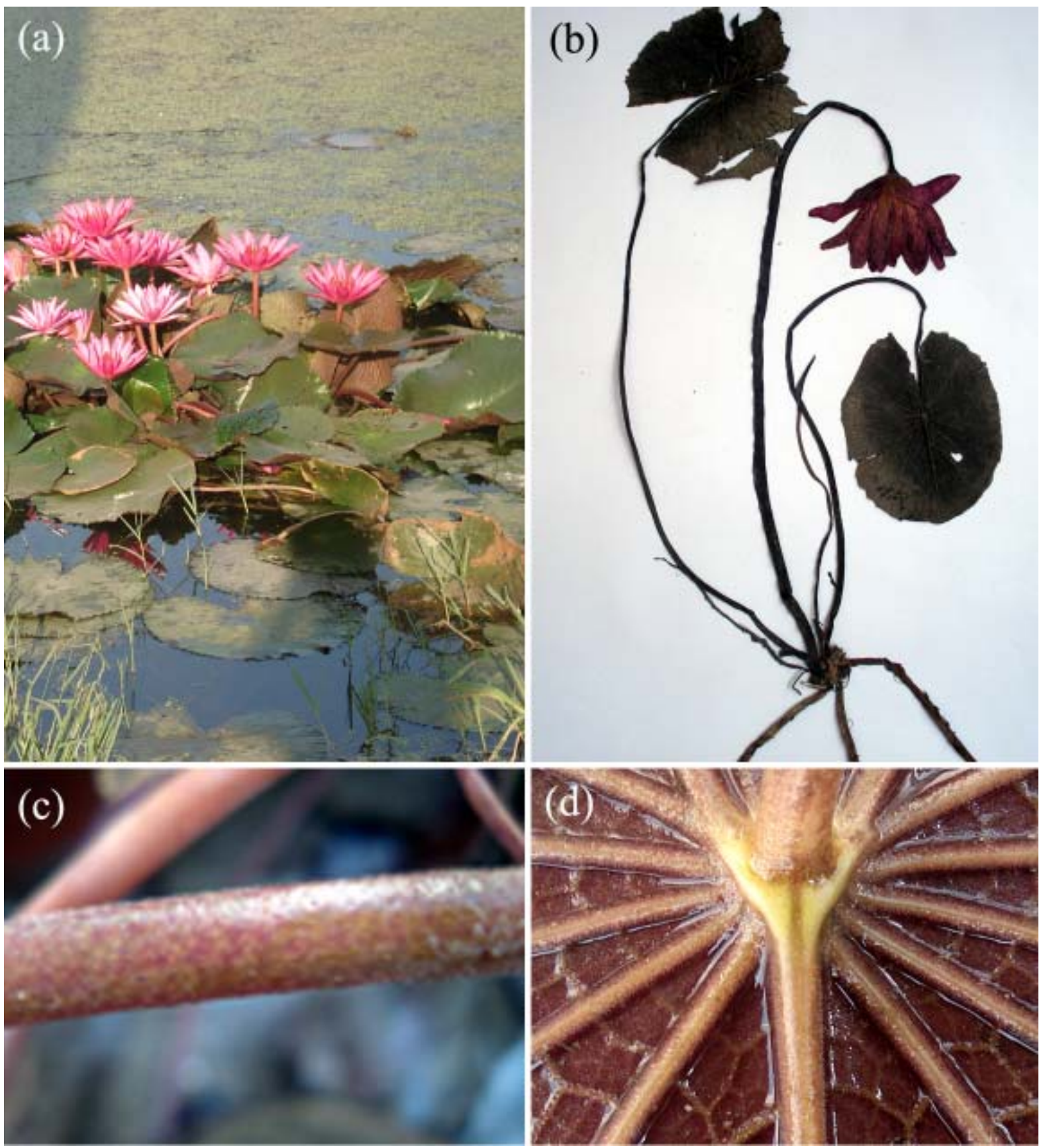

Figure 2. Nymphaea lotus var. pubescens: (a) habitat, (b) herbarium specimen, (c) hairy petiole, (d) hairy leaf. 